\title{
Exploring the Intellectual Organization of an Interdisciplinary Research Institute
}

\section{Bryce L. Allen and Brett Sutton}

\begin{abstract}
Planning and implementing library services for interdisciplinary research communities pose special challenges for academic librarians. Data were collected on journal reading patterns in an interdisciplinary research institute (the Beckman Institute at the University of Illinois at Urbana-Champaign). Analysis of these data produced a number of maps of the intellectual structure of this user community. This understanding of the structure of the academic community and how it changes over time provides a basis for developing library services that will meet the special needs of this community.
\end{abstract}

cademic libraries are sometimes in the position of providing information services to parts of the academic community that are not organized along traditional departmental lines. Specialized research institutes focusing on particular scientific problems are one example. Many campuses now have centers for the study of specialized topics ranging from cognitive science to the breeding of Chinese pigs. Interdisciplinary groups concerned with topics such as Latin American Studies or Women's Studies constitute another example of specialized institutes.

Providing services to such groups can present challenges for academic libraries that are organized according to traditional areas of subject specialization. Subject specialization, institutionalized in departmental libraries (such as a physics library or a mathematics library) or in the work of subject bibliographers, seems to be based on an assumption of a homogeneous user population. Librarians establish a specialized library or specialized services because we think there is a population of users who have similar information needs. Physics libraries are created, or physics bibliographers hired, to serve physicists and physics students. If these users did not have similar needs, the departmental library or subject specialist bibliographer would not be the best approach to service. Sometimes academic libraries are affected by institutional inertia and remain organized along traditional disciplinary boundaries even when these boundaries no longer reflect the academic communities the libraries serve. The debate con-

Bryce L. Allen and Brett Sutton are Assistant Professors in the Graduate School of Library and Information Science, University of Illinois at Urbana-Champaign, Urbana, Illinois 61801. Research for this article was done under the aegis of the Project on Scholar Communication and Information Transfer, Leigh Estabrook, Project Coordinator, and was funded in part by grants to the project from the Research Board of the University of Illinois. The authors wish to thank the federated researchers in the project, Theodore Brown, Director of the Beckman Institute, and the librarians and staff at the Beckman Institute Library for their helpful suggestions and comments. 
cerning the role of academic branch libraries is summarized admirably by Leon Shkolnik. ${ }^{1}$

Librarians, even those in specialized libraries, recognize the necessity of providing flexible service to a heterogeneous user community and know from experience that the needs of users, even within a particular discipline, are not homogeneous. At some universities, when local resources are available and interest is high, special collections are established to meet the needs of emerging user groups. For example, computer science collections emerge from mathematics and science libraries, or area studies libraries are created to meet the needs of special programs. If special collections cannot be created, some departments may establish their own informal reading rooms, although these services may be less than ideal. More often, librarians find ways to meet the needs of a heterogeneous user community by developing channels of communication within existing library structures. Subject bibliographers who develop good working relationships with faculty and students can respond to many different user needs. Collaboration among subject specialists can help to assure an appropriate balance of materials in library collections. But these labor-intensive solutions cannot always keep pace with changes in the academic community. Sometimes library users working in interdisciplinary areas may have to adapt to the traditional organization of collections and services by visiting each of the appropriate service areas in turn.

In the case of specialized research institutes or interdisciplinary working groups such as area studies departments, to assume that there is a homogeneous user population is particularly erroneous. A research institute on cognitive science, for example, may involve linguists, psychologists, and computer scientists. A Latin American Studies department may have political scientists, sociologists, and literary scholars. In situations where the population of users is not homogeneous, librarians charged with providing information service should seek systematic information about the intellectual organization of the user community. If librarians can learn more about an intellectual organization, they are in a better position to ensure that users and librarians can cooperate to provide the information people need. The library staff is able to meet the users halfway, adapting to the organization of the user community even as users adapt to the organization of the library.

\section{Librarians establish a specialized library or specialized services because we think there is a population of users who have similar information needs.}

Recent studies, including the work of Julie Hurd and Paul Metz, have demonstrated that interdisciplinary work is now widespread in academic communities. ${ }^{2.3}$ Although our work focused on an interdisciplinary research institute, we believe that the methods outlined below may have broad application as academic librarians consider the ways in which they will organize services to meet the needs of their user communities.

\section{STRUCTURE OF USER COMMUNITIES AND SERVICE PATTERNS}

The problem addressed in this research, generally stated, is: How can library service be structured for user communities that do not fit the typical department-centered or discipline-based structure? Our approach to resolving this problem was to develop ways of examining the intellectual organization of the user community. In other words, it is not enough to acknowledge that interdisciplinary research institutes seem to be structured differently from other user groups on campus. They can, theoretically, have a variety of internal organizing structures, each of which might suggest a different approach to providing library service. The challenge is to figure out how these institutes are structured. 
It is possible that an interdisciplinary research institute might promote interdisciplinary work and examine topics that can be viewed from a variety of perspectives and yet reflect, in microcosm, the usual academic organization of a university. For example, a Latin American studies unit might consist of groups of economists, political scientists, and historians who interact within their disciplinary groups but do not cross disciplinary boundaries in their research. If this were true, then the user community would be organized into a number of stable independent components, each component having its own particular information needs. In such a circumstance the library could organize its service by providing reference tools, selective dissemination of information (SDI), or collections that are tailored to the specific information needs of each component of its user community. This would be accomplished by developing a number of small "departmental" service units to meet the information needs of each of the components of the user community. But it is also possible for the user community to have a more dynamic intellectual organization in which library users do not limit themselves to materials from their own discipline. Users may cross disciplinary boundaries, working with one set of colleagues at one time, and another set of colleagues at another time. Their information needs may vary significantly from day to day. In such a dynamic situation, discretely structured information services would be counter-productive. More flexible, integrated approaches to reference, SDI, and collection building would be needed. Ideally, the organization of library services for such a user community would need to echo the complex structure of the user community. A centralized, integrated information service offering a variety of reference tools, information retrieval, and SDI would probably provide the most appropriate service to such a dynamic community. Members of the user community could select from these varied services the tools that might best meet their information needs at a particular time.
Other ways in which user communities could organize themselves require other service strategies. In some user communities, there may be hierarchical organizations of users in which information needs depend at least in part on a user's level in the hierarchy. In this type of community, services could be designed to meet the needs of each of the hierarchical levels, with new services being offered to people as they change their levels in the hierarchy. Librarians who serve businesses or work in management information systems often encounter hierarchically organized situations. An interdisciplinary research unit could be organized hierarchically, but this is certainly not traditional for academic organizations. Similarly, there may be user communities in which there is a majority group of users and one or more minority user groups. In such cases, information needs may depend on whether the user is part of the majority group or takes a minority approach to scholarship. For such a community, it might be appropriate to design information services for each of the "approaches" to the research topic. Finally, it is not uncommon for user communities to be organized around research projects. In this type of research institute, library services could be designed for each project, as suggested by Harry Llull. ${ }^{4}$

These examples illustrate the importance of understanding the intellectual structure of a user community so that librarians may offer appropriate information services to that community. Academic librarians usually have the opportunity to gain an understanding of the intellectual organization of their user communities. They see and talk to users from all parts of that community on a regular basis, participate in meetings and colloquia, and take part in the governance of their academic community. But busy librarians may not be able to participate extensively in academic affairs, and their unfamiliarity with a user community and its intellectual organization may prevent optimal planning and evaluation of information services. Our objective in this research was to explore a 
more formal means of identifying the ways in which user communities are organized, and so to provide a set of tools that might be of assistance to librarians who are faced with the task of providing information services to an interdisciplinary research institute.

\section{INDICATORS OF USER COMMUNITY STRUCTURE}

In approaching this task, we considered many of the characteristics of a user community that might serve as indicators of the intellectual organization of that community. For example, informal communication patterns are one such indicator, as are patterns of research collaboration. It is quite possible to assess who communicates with whom, and who works with whom, and to map the structure of the user community from these indicators. However, both of these indicators are relatively narrow in applicability. Identification of informal communication patterns through social network analysis is helpful, but possible only in relatively small user communities. In a large research institute or interdisciplinary studies group, particularly one in which the composition of the user community changes rapidly over time, such methods are costly and difficult to manage. Research collaboration (usually identified through coauthorship of papers) focuses on only one kind of interaction. We thought that using this indicator would provide an incomplete understanding of the nature of the user community we were studying.

From the possible indicators that we considered, we selected journal use (viewed from several perspectives) as the indicator that seemed most appropriate to our task of identifying the intellectual organization of the particular user community we studied. We assumed that if people used the same journals, they were likely to share academic interests, speak the same technical language, and to share some interest with the authors who published in the journals. In other words, people who use the same journals are closer together in the intellectual organization of a community than people who seldom or never use the same journals. This assumption is shared by Hurd and by many of the studies of interdisciplinarity she cites in the thorough literature review contained in her article. ${ }^{5}$

\section{THE RESEARCH SITE}

The library user group we studied came into existence as the result of the establishment of the Beckman Institute at the University of Illinois in 1989. Designed as an interdisciplinary research institute to investigate aspects of human and machine intelligence, the Beckman Institute brought together scholars from a variety of disciplines ranging from physics to psychology and from philosophy to computer science. Faculty and students were organized into research groups, each with designated office and laboratory space and support staff. Because these groups did not map directly onto existing academic departments, and were instead organized around general research areas, they were useful in providing a first approximation of intellectual organization.

There were, however, reasons to question the adequacy of this organizational structure as an indication of the intellectual structure of the Beckman Institute. Some of these research groups existed before the creation of the institute as natural communities of scholars sharing research interests, but others appeared to have no specific research agenda and served rather as umbrella organizations under which individual faculty pursued particular research agendas. In other cases, topics of scholarly investigation and study appeared to be shared by several groups. By focusing on journal use, an indicator of intellectual activity, we were able to identify the high-level intellectual organization of this user community, as opposed to its institutional structure. We attempted to show how the groups initially established in the institute combined into broader groups or clusters that shared research interests and perspectives.

The scholars and administrators who planned the Beckman Institute saw the 
overall collection of the University of Illinois Libraries as supportive of the research and instruction of the institute. A special academic library was included within the institute, designed primarily as a service point rather than as a collection. The Beckman Institute Library established a small collection of highly used journals, but the greatest emphasis in this library was on the provision of electronic access to information through locally generated and mounted databases, CD-ROM bibliographic services, and online searching. Another important service was a heavily used article copy service, in which photocopies of articles from journals were requested by Beckman Institute faculty and students, and provided free of charge by the library from the University Library's collections, or through interlibrary loan.

Our objective in this research was to explore a more formal means of identifying the ways in which user communities are organized, and so to provide a set of tools that might be of assistance to librarians who are faced with the task of providing information services to an interdisciplinary research institute.

The objectives of this research were to explore means of data collection and analysis that reveal the intellectual structure of a user community. We were interested in investigating a variety of ways to obtain insights about the high-level organization of scholars (faculty and students) within an interdisciplinary research institute. As a secondary objective, we wanted to identify methods of analysis that could be used by professional librarians. We used a variety of microcomputer hardware and software that would be available to many professionals in academic libraries. In other words, we wanted not only to explore the intellectual organization of one research community, but to do so in a way that would benefit professionals working with similar research communities.

\section{DATA COLLECTION}

Data on the journal reading patterns of members of the user community of the Beckman Institute Library were gathered in three ways. As part of a larger project examining scholarly communication and information transfer within the institute, all full-time faculty members appointed to the institute were interviewed using a structured interview schedule. One set of questions asked faculty members to identify the journals they read regularly in connection with their research. Responses to these questions were aggregated by research group for analysis, so that the results could be presented anonymously. The frequency with which journal titles were mentioned by all of the faculty within a research group was tabulated into a separate journal list for each research group. Although this mechanism suppressed differences between scholars within groups, it provided a data set that was ideal for establishing the higher-level intellectual organization of the institute.

The second data collection was accomplished with the cooperation of the Beckman Institute Library. Records of the article copy service were summarized in such a way that individual users' reading could not be identified. These data were aggregated into a similar set of journal lists for each research group for each of the first four academic terms in which the service was offered. Each list also contained the frequency with which articles from a particular journal were requested by users associated with a particular research group. These lists were further aggregated into a single list of the first fourteen months of the service for each department. The data from the article copy service were less complete than the interview data in certain ways. Some of the members of the user community who were interviewed made no use of the library's service, and so were not included in the article copy service data. Similarly, we assumed that scholars do not request from the library photocopies of articles from journals to which they subscribe. As a result, these data did not include 
some of the central reading habits of members of the user community. However, the data from the library article photocopy service were also more complete than the interview data in some ways. Articles requested by all members of the user community were recorded, so reading patterns of the students of the institute as well as of its faculty were included. Also, articles were requested from many journals that would not have been considered as "read regularly." As a result, a broader picture of reading patterns was obtained from the library data.

If librarians can learn more about an intellectual organization, they are in a better position to ensure that users and librarians can cooperate to provide the information people need.

The third method of data collection involved scanning three current years of citation indexes (both Science Citation Index and Social Science (itation Index) for articles written by faculty from the Beckman Institute. The citation records from each citation index entry were copied into a database that allowed us to compile a list of all of the journals cited by scholars from each research group. In this case, citations from published articles were taken as evidence of the reading patterns of the members of the user community. There are a number of advantages in this type of data. Because the data are publicly available, this approach to data collection is unobtrusive. Because authors usually cite articles directly relevant to their scholarly work, citations provide a reliable measure of the information that the scholars think is important. There are also some disadvantages associated with using citation data to explore the intellectual structure of a user community. Citations may reflect previous reading, rather than current research interests, and so may be less relevant to the current intellectual structure of the community than the other measures used in this research. In the case of articles coauthored by scholars from outside the user community, we do not know whether the citations reflect the reading of members of the user community or that of the coauthors. In addition, this method of data collection is constrained by the selection of source articles by Institute for Scientific Information, the producer of the citation indexes. It is possible that citations from articles not covered by the citation indexes would have added to our understanding of the intellectual structure of the community. Finally, these data require considerable database expertise to convert the citation index entries into lists of journals consulted by groups of scholars.

Identifying the same variable (in this case, journal use patterns) through different types of data provides many advantages. In this study, there were rea-

TABLE 1

\section{COMPARISON OF THREE SOURCES OF JOURNAL USE DATA}

\begin{tabular}{|c|c|c|}
\hline Source of Data & Advantages & Disadvantages \\
\hline \multirow[t]{4}{*}{ Survey } & Direct & Possibly incomplete \\
\hline & Provides contextual information & Subject to selective recall \\
\hline & Stresses most used titles & Obtrusive \\
\hline & & Provides title, not frequency of use \\
\hline \multirow[t]{3}{*}{ Copy Service } & Reflects current interests & Does not include some scholars \\
\hline & Unobtrusive & May not reflect all journal reading \\
\hline & Provides frequency of use & \\
\hline \multirow[t]{4}{*}{ Citations } & Broader base & May reflect previous reading \\
\hline & Unobtrusive & May overemphasize peripheral subjects \\
\hline & Multidisciplinary & Limited by ISI coverage \\
\hline & Provides frequency of use & May reflect reading of co-author \\
\hline
\end{tabular}


sonably high correlations ( $r=.52$ to .62 ) between the similarity matrices produced from the three types of data, so we were confident that these different approaches were reliable measures of journal use. It would have been possible to combine the results into a single index of journal use, but we thought that separate analyses of the data would reflect their richness, and would allow the advantages of individual measures of journal use to compensate for the disadvantages of other measures. Table 1 outlines our perception of the advantages and disadvantages of each of the three approaches to data collection that were used in this research.

\section{DATA ANALYSIS}

The lists of journals consulted by members of research groups were analyzed to produce a cosine similarity measure for each pair of groups. The cosine measure is a value between 0 and 1 reflecting the similarity between pairs of groups, based on the frequency with which the same journals were mentioned or requested by members of those groups. The result was a matrix of similarities that showed how similar each group was to every other group. The similarity matrices formed input to two additional kinds of analysis. The first was multidimensional scaling, which produces a two-dimensional configuration. It creates a map of the intellectual community, with groups shown to be similar to each other appearing closer together on the map and with dissimilar groups farther apart. The second analysis was hierarchical cluster analysis. This analysis placed research groups with similar journal use patterns into higher-level clusters. These clusters were then located on the two-dimensional maps produced by multidimensional scaling. Frequently this type of analysis has been helpful in understanding the intellectual structure of disciplines; technical details are provided in articles by Katherine N. McCain and by Henry Small and E. Sweeney. ${ }^{6,78}$

Lists of journals consulted by groups of scholars can also be used to generate similarity measurements between jour- nals. If two journals are consistently read by the same people, it is assumed that their content is similar. In the case of the interview data, similarities between journals were identified using cosine measures. This allowed a map of journal titles, analogous to the maps of the intellectual community, to be created. In addition, simultaneous clustering of journals and groups showed which parts of the user community were most closely associated with the use of particular clusters of journal titles.

\section{FINDINGS}

\section{Comparison of Data from Three Sources}

Interview Data. The faculty appointed to the Beckman Institute were interviewed to assess a variety of issues related to information gathering and scholarly communication. As part of these interviews, scholars were asked to identify the journals they regularly consulted in connection with their research. Figure 1 presents the clusters of groups identified on the basis of the responses of the researchers during these interviews.

This map presents the result of the analysis of the interview data described above. Before moving to a discussion of the differences between this map and those produced from other data, it may be helpful to outline the main features of all the maps. Each letter represents a research group. For example, in the Psychology cluster, the letters represent groups with names like "Cognitive Neuroscience" and "Visual Processing." The groups whose reading patterns were similar are closer together on the map. Normal maps have an orientation (for example, north at the top) that helps users read them. Regarding the type of map created in this project, the orientation of the map is a matter for interpretation. It seemed clear to us that the top of the map contained groups who adopted approaches that might be called "scientific" while those toward the bottom seem to have adopted engineering approaches. Toward the top, for instance, are groups investigating neuronal patterns and other aspects of cognitive science, while toward the bottom are 


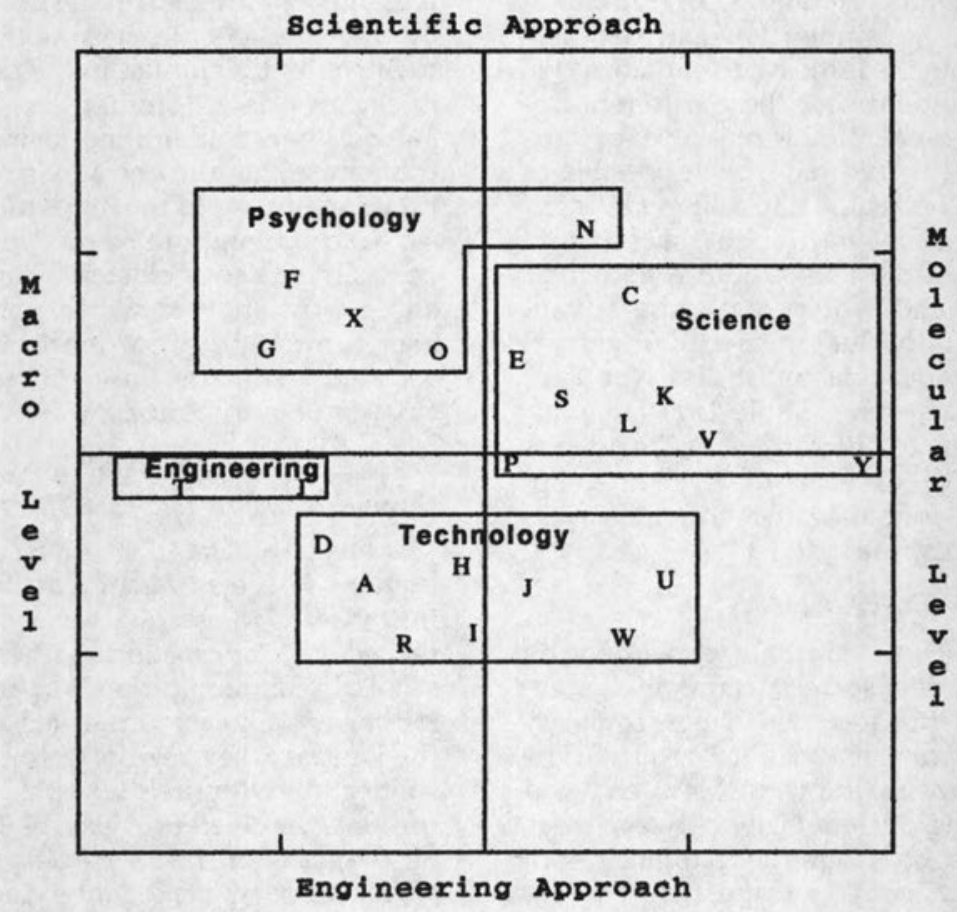

FIGURE 1

Clusters from Interview Data

groups investigating organometallic materials or decision processes in computerized networks. The other "direction" on the map was more difficult to interpret. At first, we thought that social science was on the left and pure science on the right. Since a number of engineering groups were found on the left, this interpretation was inappropriate. Our final interpretation of the horizontal dimension on this map was that groups toward the right of the map are concerned with phenomena at the molecular level (or even atomic level) while those to the left of the map are concerned with what we have called the "macro" level. Toward the right of the map are groups doing scanning tunneling microscopy and working on materials chemistry, while to the left are groups investigating much larger phenomena, such as the architecture of intelligent systems (including the brain).
The cluster boundaries superimposed on the letters represent the results of cluster analysis, in which similar groups were placed into high-level clusters. The labels assigned to these clusters are based on our interpretation of the common interests in the research groups represented in each cluster. For example, the Science cluster contains groups like "Molecular Biophysics" and "Prokaryote Genome Analysis." A comparison of the different views of the user community presented in this article will show that there appear to be six of these high-level clusters in the Beckman Institute (Applied Science, Artificial Intelligence, Engineering, Psychology, Science and Technology), but that the boundaries between some of the clusters are not well defined in some of the data.

Library Article Photocopy Service Data. Over fourteen months, careful records were made of all journal titles 


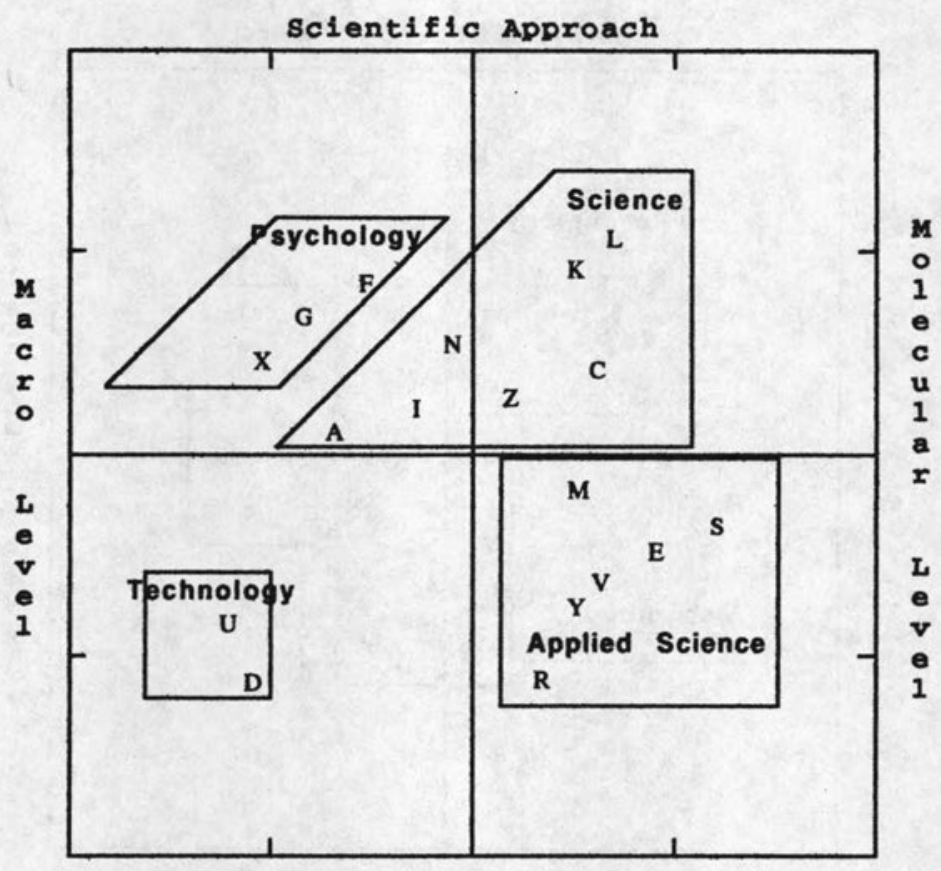

Engineering Approach

FIGURE 2

Clusters from Article Copy Service Data

requested by faculty and students of the Beckman Institute from the Beckman Library. From these lists, a map of intellectual structure of the user community based on actual reading patterns rather than reported reading patterns was derived. Figure 2 shows the clusters of groups identified on the basis of fourteen months of data from the article photocopy service.

The similarities between this map of the intellectual structure of the community and the one produced from interview data are clear. For example, the Psychology and Science clusters are roughly the same. There are also a number of important differences between the two data sets that are illustrated by these two figures. The first difference is that the Engineering cluster identified through interviews is absent from the library data. It would appear that re- searchers in this cluster made little or no use of the library's article copy service. In other words, the interview data identified a group of potential library users in the intellectual community who were not making use of one of the important services of the library.

On the other hand, the library data showed a clear difference between the Applied Science and Technology clusters that had been grouped together as a Technology cluster based on the interview data. This seems to indicate that there are a few main journals shared by these clusters and all of the scholars mentioned these journals in the interviews. However, when detailed evidence of reading was examined, it showed that there was sufficient difference in reading patterns to create two separate groups. Because of the additional detail provided by the library data, a clearer picture of the con- 
Scientific Approach

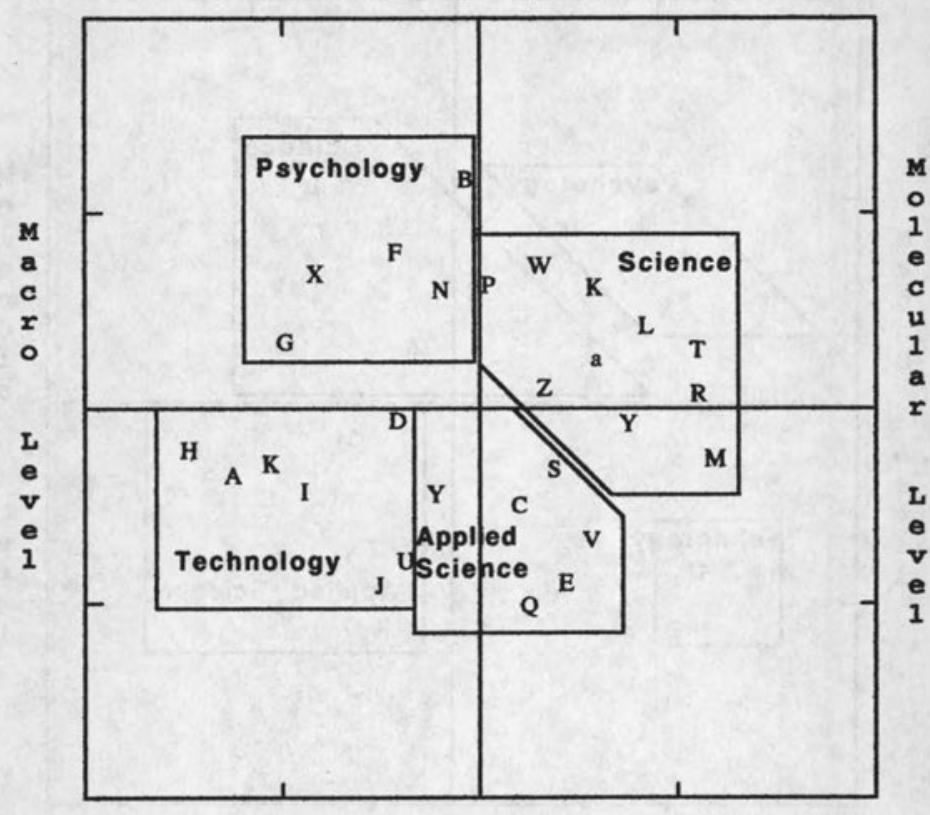

Engineering Approach

FIGURE 3

Clusters from Citation Data

figuration of the intellectual community emerged.

Although it is difficult to see differences in detail by examining the maps, the analysis of these two types of data showed that some of the research groups were included in one cluster based on the interview data, and in a different cluster based on the library data. For example, group $\mathrm{N}$ appears in the Psychology cluster in the maps based on interview and citation data, in the Science cluster in the map based on the library data, and even in the Applied Science Cluster in one of the longitudinal maps discussed below. These groups are of great potential interest, because they seem to be located at the boundary between clusters. Such boundary-spanning groups can perform an essential role in the development of an intellectual community. From the perspective of library service, they are likely to require a broader range of information than groups consistently found in the same cluster. In other words, boundary-spanning groups defy traditional approaches to library service, and require innovative approaches by library professionals to meet their wideranging information needs.

Citation Data. Figure 3 is a map of the intellectual community of the Beckman Institute based on citation data.

Clearly, this map resulted from a very different kind of data, and it is not surprising that there are a number of differences between this map and those presented above in the relative location of the clusters. In addition, more groups appear on this map than on the map generated from library data, because all publishing faculty were included, whether or not they made use of the library photocopy service. Thus there is more detail 


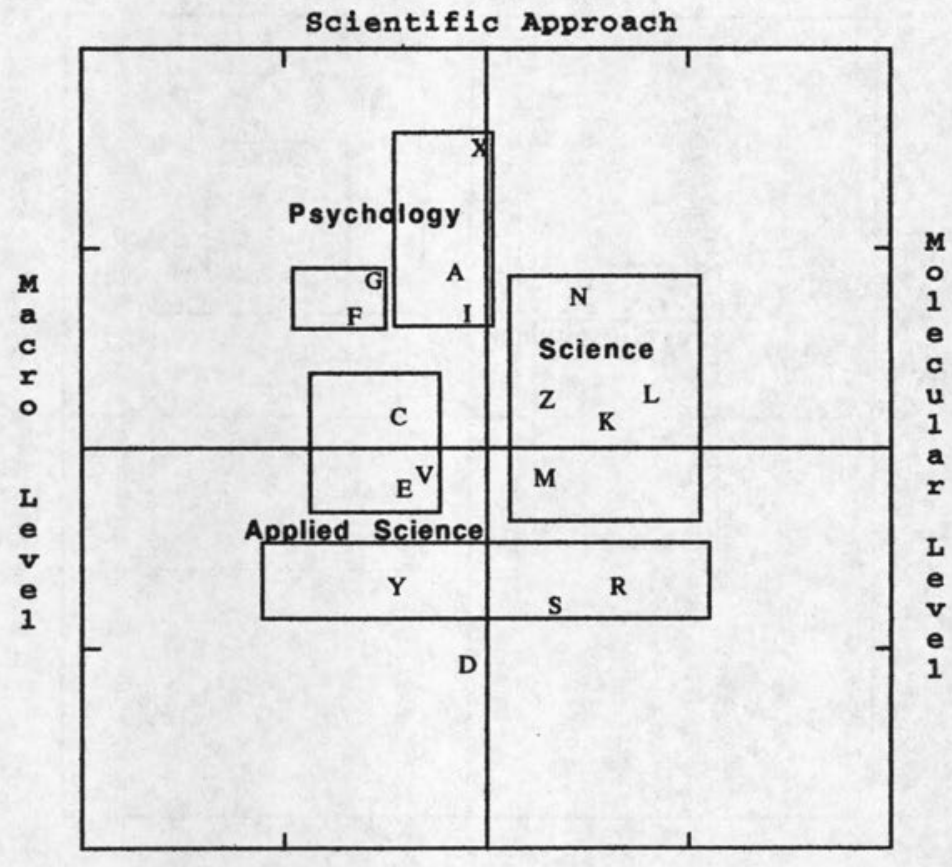

Engineering Approach

FIGURE 4

Clusters from Article Copy Service, June/December 1990 (2,380 Uses)

on this map. However, the similarities among the versions of the intellectual structure of this user community produced by the three different sources of data on reading patterns are striking.

\section{Longitudinal Analysis of Library Data}

Figures 4, 5, 6 and 7 show how the intellectual organization of the user community changed over a period of eighteen months. We believed that analyzing the library data would provide an appropriate longitudinal view of these changes. Repeated interviews would have provided comparable data, but they would have required considerable intrusion into the user community. In addition, the data from the library article photocopy service were more sensitive to small-scale changes in reading patterns than the citation data. One final consideration in this choice was the fact that library users were likely to be requesting materials to which they did not routinely have access (through personal subscriptions, for example). We thought that this made the library data more indicative of emerging interests, and particularly of cross-disciplinary interests.

It is possible to examine the evolution of the user community by considering each of the main clusters in turn. The Psychology cluster initially had two components, one more applied than the other. These two clusters eventually merged. The Science cluster has maintained a relatively consistent core of research groups, but there has been some migration back and forth between this cluster and the Applied Science clusters. Like the Psychology cluster, the Applied Science cluster has two components, which separated and combined at different points in time. It appears to be one of 


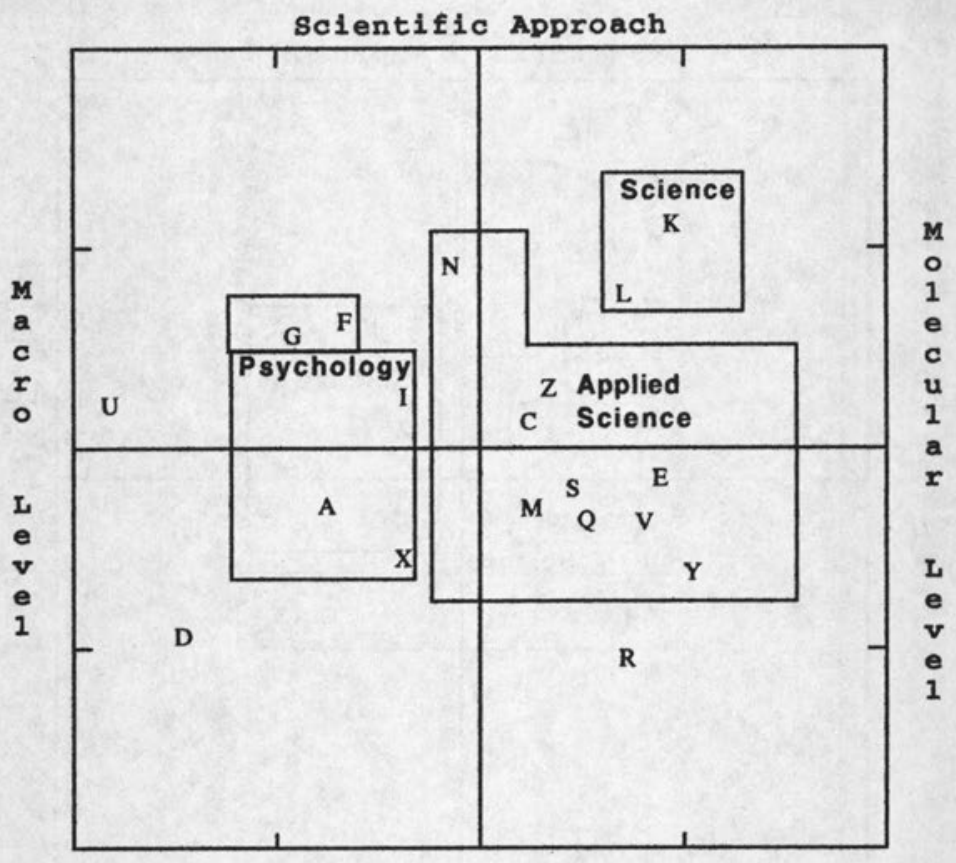

Engineering Approach

FIGURE 5

Clusters from Article Copy Service, January/May 1991 (2,410 Uses)

the more dynamic clusters, with groups shifting between the Applied Science and the Science cluster, although there is a relatively consistent core of groups. In summary, this user community exhibits a great deal of dynamism, which may be important in designing information services for the community.

\section{Reading Patterns as Journal Clusters}

Most libraries in North America use broad, general-purpose classification schemes to organize their collections and to assist in the identification and retrieval of information. Although such schemes have the advantage of being applicable to a large variety of library situations, sometimes they may be too inflexible to be used successfully in a specialized research institute. Analysis of the kind discussed here can provide an alternative for classification of library materials and for information retrieval in a specialized environment. In essence, the alternative classification emerges from an analysis of the extent to which scholars view titles as meeting the same information need. For example, the lists of journals developed for each research group from interview data were analyzed to produce similarity measures between journals. If scholars frequently cited the same two journals as relevant to their research interest, this indicated that the journals were similar in subject coverage. After similarity measures were calculated for all journals, multidimensional scaling and cluster analysis were used to produce a map of the journal literature.

Figure 8 shows the organization of journal titles revealed by the responses in interviews. Each dot represents a journal title, and journals that appear close 


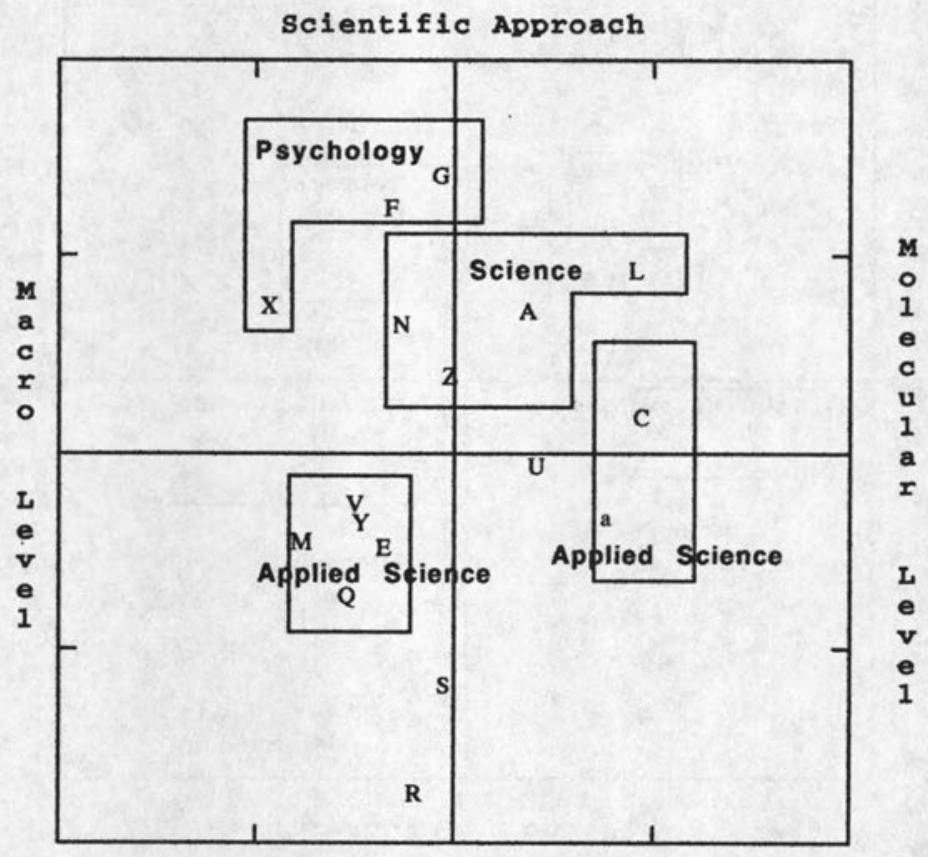

Engineering Approach

FIGURE 6

Clusters from Article Copy Service, May/August 1991 (2,248 Uses)

to each other were more likely to have been cited as being read frequently by the same scholars.

This journal map is similar in many respects to the maps of the intellectual structure of the user community. This is hardly surprising, since it is based on similar analysis of the data used to create the intellectual structure maps.

Simultaneous clustering of scholars and journals can provide a direct association between clusters of users and clusters of journals. This was done for the interview data, and table 2 provides an illustrative output. It shows (as one would expect), that Psychology journals are primarily associated with the Psychology cluster. More revealing is the nature of these journals. Rather than emphasizing the full range of journals in Psychology, this cluster of library users appears to be focusing upon physiologi-

\section{TABLE 2}

JOURNALS ASSOCIATED WITH THE PSYCHOLOGY CLUSTER

Behavioral and Brain Sciences
Cognition
Cognitive Psychology
Cognitive Science
Electronencephalography and Clinical
Neurophysiology
Journal of Experimental Psychology: General
Journal of Experimental Psychology: Human
Perception and Performance
Journal of Experimental Psychology: Learning,
Memory and Cognition
Journal of Neuroscience
Neuropsychologia
Neuroscience
Psychological Review
Psychophysiology




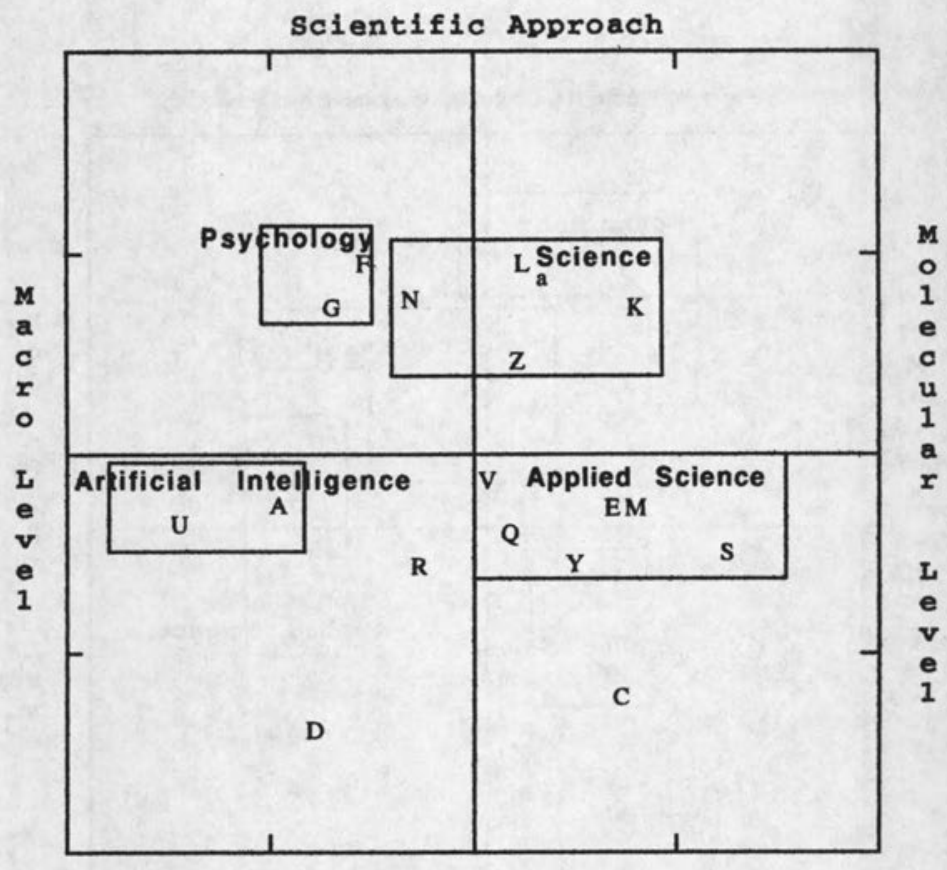

Engineering Approach

FIGURE 7

Clusters from Article Copy Service, September/December 1991 (3,273 Uses)

cal psychology and cognitive psychology. Details of this sort may be most useful in planning services such as SDI for segments of user communities.

\section{SUMMARY OF THE MAPPING TECHNIQUE}

The three methods of data collection used in this research identified an organizational pattern among the library user community associated with the Beckman Institute. Data from interviews with scholars, citation analysis, and patterns of use of one specialized library service contributed to this understanding of the user community. Each type of data collection had advantages and disadvantages, and differences among the data suggest that any librarian who wants to explore a user community should make use of more than one data source.
The data were collected, aggregated, and analyzed using a variety of microcomputer hardware and software that would be available to many academic librarians. The interview data were transcribed and entered into text files on IBM-PC clones. A utility program was written to scan each text file in turn and to aggregate answers to the same questions into a separate file. Data from this file were entered into a standard spreadsheet (in this case, MS Excel) to create the lists of journals identified by groups of scholars as being regularly used. Cosine similarity measures were calculated by a small program written in BASIC, although SPSS-PC + could have been used. Multidimensional scaling and cluster analysis were done on the Macintosh version of SYSTAT, although SPSS-PC+ would have produced the same output. 


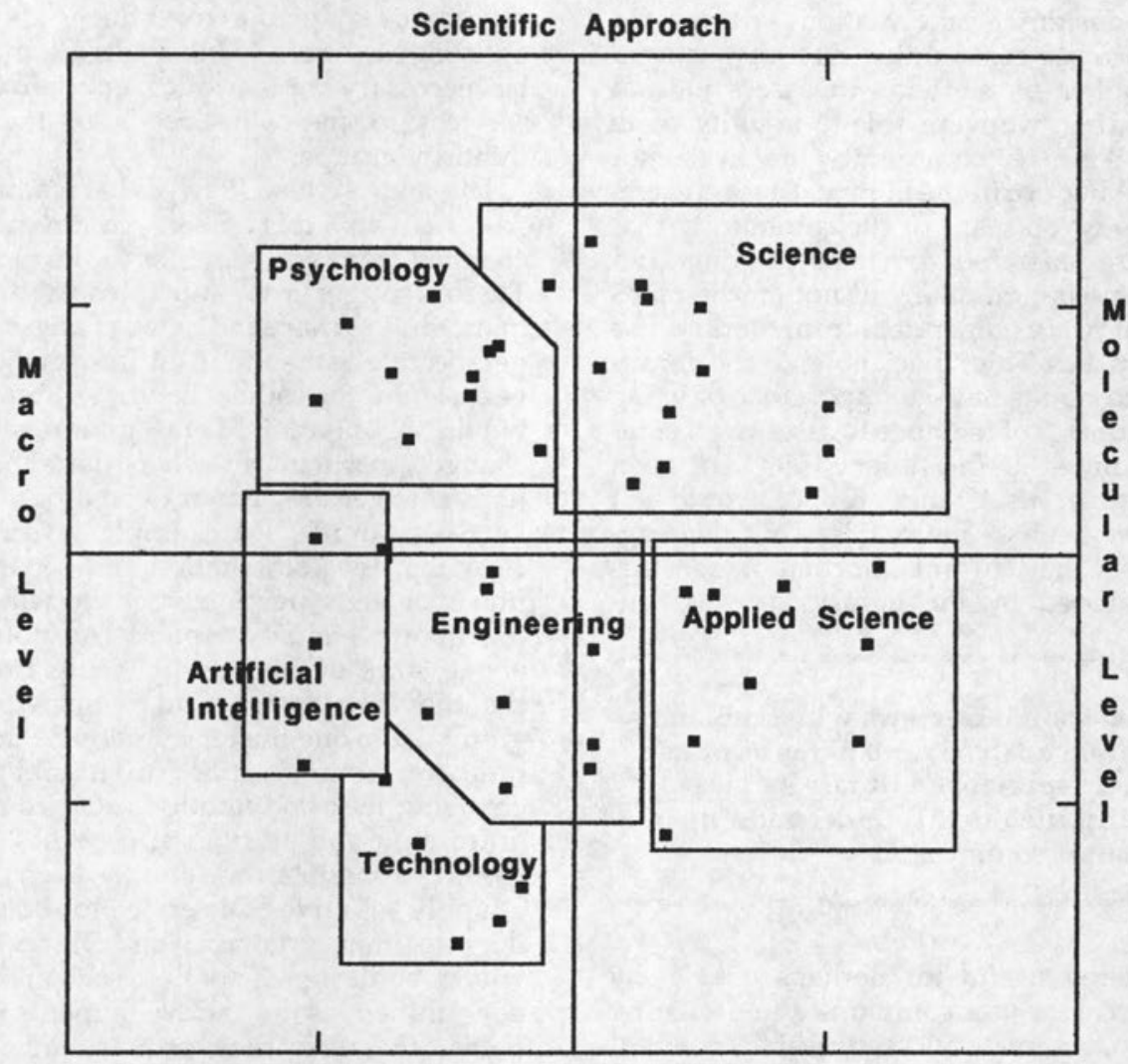

Engineering Approach

\section{FIGURE 8}

Journal Clusters from Interview Data

The citation data were downloaded from the online (DIALOG) version of Social Science Citation Index and the CDROM version of Science Citation Index. They were imported into an INFORMIX database, using a program written in C to convert the text files into structured files for entry into appropriate fields in the database. Because of available resources in the School where we were working, we used a UNIX version of INFORMIX, but this version is very similar to that available for the MS-DOS environment. Again, any programmable relational database on a microcomputer would be able to manage this data and produce the necessary output. Because off-the-shelf hardware and software were used in this project, and because only moderate computer, database, and statistical expertise were employed, the methods of data collection and analysis illustrated here could be adopted by many academic librarians who wish to explore the intellectual organization of their user communities.

\section{CONCLUSIONS}

In this section, we summarize the results of this investigation of the intellectual structure of the library user community from one interdisciplinary research institute, and suggest how these results might be taken into account 
in designing information services for that user community. First, by using a number of methods to assess journal reading, we were able to identify parts of this user community that were not making use of the library. These clusters appear on maps of the community that were generated from interview data, and from citation data, but not on the maps that were generated from library use statistics. This "black hole" in the library data points out the importance of using a number of methods to assess user communities. If the library data had been used by itself, this absence would not have been as noticeable. This also suggests that current information services provided by the library are not con-

Data from interviews with scholars, citation analysis, and patterns of use of one specialized library service contributed to this understanding of the user community.

sidered useful (or perhaps usable) by part of the user community. Redesigning information services to meet the needs of these clusters is a challenge that the library staff may wish to address.

Another insight emerges from these maps. Some research groups were excluded from the high-level clusters that made up the intellectual structure of the community. Providing library service to outlying members of a user community can be another challenge for a library. Frequently, we establish services to meet the needs of the majority, and so tend to disregard the needs of the minority. One of the great values of this kind of analysis of intellectual structure of a user community is that it identifies minorities: small clusters and clusters of one. Equipped with an understanding of this intellectual structure, librarians are in a position to explore the special information needs of minority users, and to establish programs that meet those needs. In some cases, services that meet the needs of the main clusters in the commu- nity can be adapted to meet the needs of outlying members. In other cases, it may be necessary to consider specialized services to meet the needs of those minority groups.

This analysis also showed that reading patterns in this user community changed from one semester to the next. These changes were not always dramatic, and perhaps indicated changes in perspective rather than in information needs. On the other hand, a library would be ill-advised to ignore such changes, particularly when the shortterm changes are shown to be a part of long-term trends. For example, it seems clear that the combination and separation of clusters are phenomena to which the library should respond. As noted above, some of this activity results from the movement of boundary-spanning groups from one cluster to another. Planning for library service to a rapidly changing user community seems to require new and flexible approaches. It would be possible, for example, to create a highly selective SDI service for boundary-spanning scholars. This SDI service would be designed to alert scholars to new initiatives and developments in fields other than their primary area of research interest. This kind of wideranging SDI is quite different from usual library services that are keyed to a narrow interest profile. A case can be made for a service that would identify important developments in all areas except the narrow area of subject interest of a user.

Some of the semester-to-semester changes in reading patterns result from the addition of new individuals and groups to the Beckman Institute, and from the departure of some individuals and groups from the user community. Thus this user community is dynamic in this sense as well as in the ways discussed above. The rate at which groups have come into the institute, and have begun to make full use of the facilities of the institute (including the library) has varied considerably. Therefore, library service must be flexible enough to meet the needs of a rapidly changing user community. 
Finally, the classification of journal titles that emerged from this research could be used in conjunction with the maps of the high-level structure of the user community to provide specific services. For example, tables of contents from journals associated with user clusters could be routed to those users. Another use of this emergent classification might be in providing access to online searching. The databases that cover a cluster of journals could be made directly available to users from the associated user cluster, while databases covering other journal clusters might be made available primarily in an intermediated mode to those users. We do not mean to suggest that this kind of classification is useful for organizing the library's collection. Because it emerges from a dynamic intellectual organization of the user community, the classification is likely to change too quickly to allow its use for an essentially static function such as the organization of the library collection. Rather, it is of greatest use in the organization of services such as database searching or SDI, whether or not such services make direct use of a particular collection. In addition, emergent classifications of this sort may serve to point out to scholars relationships between research topics of which they were not initially aware.

Equipped with an understanding of this intellectual structure, librarians are in a position to explore the special information needs of minority users, and to establish programs that meet those needs.

In summary, analyzing the intellectual structure of the user community can provide important insights about how that community functions, and accordingly about how its information needs might be met. We believe that this type of mapping is within the technical capabilities of many academic librarians, and that it can be useful to them as they consider the difficult issues associated with providing information services to an interdisciplinary research institute.

\section{REFERENCES AND NOTES}

1. Leon Shkolnik, "The Continuing Debate over Academic Branch Libraries," College \& Research Libraries 52(July 1991): 343-51.

2. Julie M. Hurd, "Interdisciplinary Research in the Sciences: Implications for Library Organization," College \& Research Libraries 53(July 1992): 283-97.

3. Paul Metz, The Landscape of Literatures: Use of Subject Collections in a University Library, ACRL Publications in Librarianship, no. 43 (Chicago: ALA, 1983).

4. Harry Llull, "Meeting the Academic and Research Information Needs of Scientists and Engineers in the University Environment," Science \& Technology Libraries 11(Spring 1990): 83-90.

5. Hurd, "Interdisciplinary Research in the Sciences."

6. Katherine W. McCain, "Cocited Author Mapping as a Valid Representation of Intellectual Structure," Journal of the American Society for Information Science 37(1986):111-22.

7. Katherine W. McCain, "Mapping Authors in Intellectual Space: A Technical Overview," Journal of the American Society for Information Science 41(1990): 360-68.

8. Henry Small and E. Sweeney, "Clustering the Science Citation Index Using Co-Citations I: A Comparison of Methods," Scientometrics 7(1985):393-409. 


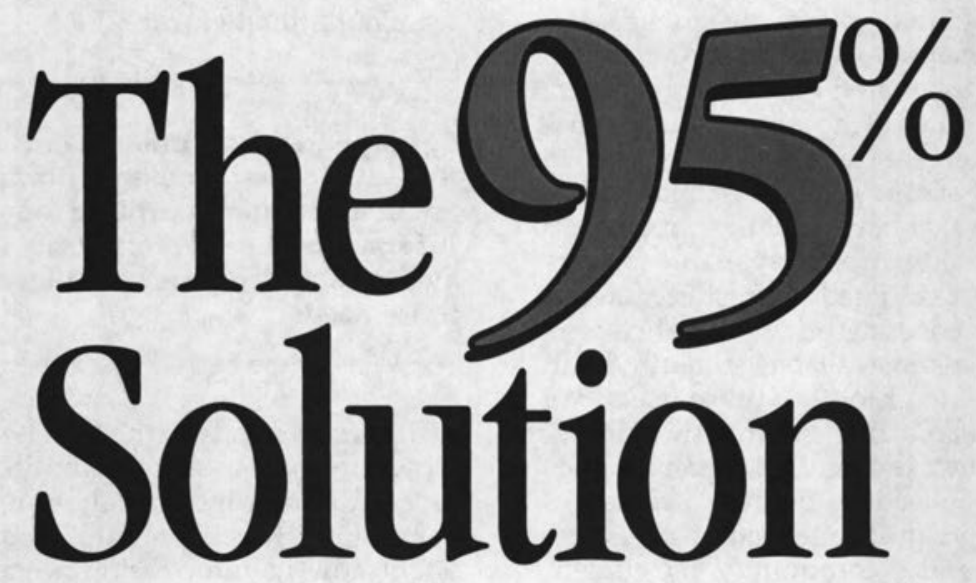

You get one chance with authority control, so it's important to get it done right. LTI guarantees that its affordable, machine-only authority control will link $95 \%$ or more of your library's controlled headings to an LC or LTI authority record. No exceptions! No excuses!

When manual review is requested, only professional librarians are used as editors and link rates approach $100 \%$.

LTI maintains the complete LC MARC authority files (updated weekly), supplemented with over 410,000 LTI authority records and 350,000 proprietary "cross links."

Contact LTI for more information on authority record link results.

"Authority Control for the 21st Century"

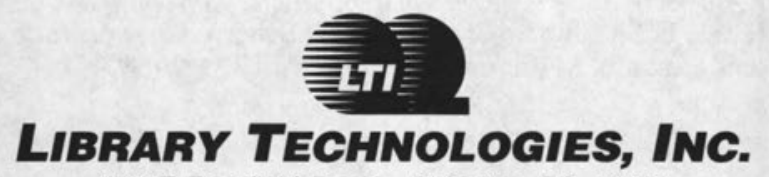

1142E Bradfield Road Abington, PA 19001

(215) 576-6983 Fax: (215) 576-0137

(800) $795-9504$ 